\title{
English-oriented ICTs and ethnic language survival strategies in Africa
}

\author{
Oladokun Omojola
}

\begin{abstract}
This paper takes a critical look at information and communication technologies (ICTs) and asserts that the advantages and opportunities which they purportedly offer should not be exaggerated within the context of indigenous populations of Africa, most of which use ICT gadgets and applications that are built into languages alien to them. This scenario is reminiscent of technological determinism which assumes that the target users of ICTs should be able to understand the language in which the technologies are crafted. Unfortunately, the inability of indigenous peoples to adequately comprehend these technologies, as a result of language hindrances, has dramatically eroded the professed socio-economic benefits of ICTs and creates a sore point in the globalisation process, which these technologies drive. Attempted resolution of this colossal deficiency, by a few discerning makers of ICTs, has not succeeded and, in fact, has the potential of complicating the problem. This paper concludes that the solution to the challenge is still feasible within the domain of Afrocomplementarism, which promotes the convergence of indigenous contents and Western technologies. The process should start with local initiatives in developing indigenous languages. By imbuing local and global (such as the Internet) media with indigenous language content, the potential exists for raising awareness amongst ICT producers and encouraging them to develop technologies to accommodate these languages.
\end{abstract}

\section{Keywords: afrocentricism, afrocomplementarism, English, ICTs, indigenous population, Western.}

Colonialism, besides the associated stories of economic exploitation, political subjugation and fierce wars of independence, also has another crucial ramification of socio-cultural subservience. The upshot of that subservience is specified in the domain of culture, where culture is defined in terms of the means of communication or the embedded language (Hoffman, 1989:118; MacGregor \& Price, 1999:449). Salawu (2006:2) has also noted that 'language is the most characteristic element of a people's culture.' In African countries, colonialism left a legacy of acculturation, which glorified the imperialist language into the lingua franca but humbled hitherto vibrant local languages into second positions and sometimes no position at all. For instance, the trend in Nigeria, which was colonised by Britain, has been to regard fluency in the English language as elitist while those who cannot speak the language comfortably are regarded, erroneously in many cases, as illiterates. This scenario is worse in francophone systems. In many 
African countries with a colonial past, three categories seem to have emerged with regard to proficiency in a foreign, colonial language: those who can write or speak it fluently; those who struggle with the language and the folks who can hardly write or speak it. This categorisation is a major issue with regard to ICTs.

The 'elite' class of fluent speakers seems to offer eloquent potential access to the various ICT systems and this assertion has been verified in Tanzania where 'only a minority of wellresourced, urban and/or international NGOs has access to ICT facilities' (Mercer, 2004:49). Academics, upscale professionals, most civil servants, few students of tertiary institutions and the like are expected members of this category. The second group of strugglers, many of whom find solace in pidgin English, is hardly a target of ICT makers. Members of the third group are several years away from ICTs and it will take a deliberate government travailing to get them on the ICT track.

Unfortunately, the last group still forms the bulk of the indigenous African population which is widely regarded as far removed from the globalising world, while millions who aspire to the first group are finding it very hard to achieve that 'feat'. Prominent among these strugglers are students who seek admissions into universities and other tertiary institutions. Besides that, even the elite class is dwindling by the day, owing to the brain drain which has seen many bright brains travel out in search of so-called greener pastures. For instance, in a report presented some years ago by Cogburn and Adeya (1999:12) no fewer than 30, 000 Africans with second or third degrees were earning their livelihood outside their continent. Nigerians account for a significant part of this figure.

The question at this point is: what is the implication of this classification with regard to ICTs? This question can be answered in the light of the benefits that ICTs purportedly offer. The indigenous population of a country, most of which cannot read or write, is usually on the lower rungs of the social ladder. Their culture is at the mercy of foreign forces, they suffer environmental degradation and infrastructural inadequacy, unrewarded exploitation of natural resources, poverty, neglect by the ruling class, lack of basic amenities, invasion of land rights and so on. ICTs are supposed to offer succour by offering opportunities to deal with these abnormalities and wickedness. They should provide resources that come in the form of technological tools. These tools help to communicate, disseminate and assimilate, store, retrieve, manipulate or manage information resources in a manner that bring improvement in the socioeconomic and democratic lives of those who use them. In the area of education, for instance, the convergence of computers and the internet can drastically enhance learning in both formal and informal settings.

\section{The problem statement}

Are the ICTs fulfilling the role as a promoter of socio-economic development? The starting point of the answer to this question is the identification of the ICTs that are available to the indigenous population. With regard to older technologies, the telephone has penetrated far deeper into Africa. The introduction of the more modern Global Systems of Mobile Telecommunication 
(GSM) has put the telecommunication interests of the rural population under the radar and the rural folks might not need to travel too far a distance to have access. In the KwaZulu territory of South Africa, the short message service (SMS) is being deployed by the UmNyango Project to send information regarding violence against women and children. Internally displaced persons, in the war going on in some parts of Uganda, are taking advantage of the Internet telephone facilities to tell their stories. SchoolNet Africa, a non-governmental organization is empowering children in war-ravaged countries including Rwanda, Liberia and Angola. In Sierra Leone, another NGO - International Education and Research Network has used ICTs for education and peace building. Besides that, community-based tele-centers are being established by the governments of many African countries to cater to the telecommunication needs of the people in the countryside, pending the time a full telecommunication coverage will be available. Radio has been the traditional medium that indigenous populations can claim proper access to. Television is also becoming popular among indigenous populations. ICTs offer potent opportunities for empowerment. Most of these laudable projects, however, are bedeviled with challenges. One of these is whether or not these ICTs which are made available in foreign languages can actually impact on the indigenous population who hardly understand these foreign languages.

The most recent ICTs, which come in the form of audio-visual systems, internet, intranet and extranet, have multidimensional benefits that cannot be ignored. They promote e-learning and this enhancement has extended to web-based systems. When these new technologies are used alongside the traditional classroom practices, they create blended learning, which is in recognition that the best of learning is achieved when it takes from the two perspectives. Search engines like Google, Yahoo and Lycos have created the platform from which information from any part of the world can be accessed - as long you have the right equipment and you understand the language of communication. Internet browsers such as Netscape, Internet Explorer. Firefox and Opera, among others, are written in major languages of the world and indigenous languages are never included. The same applies to contemporary gadgets such as personal digital assistants (PDAs), 3.5G cell phones, MP3, MP4 players and so on.

The inability of indigenous populations to benefit from these contemporary technologies has, over the years, been attributed to different reasons. These include affordability challenges, lack of electricity, illiteracy, low computer penetration and so on. This paper deals with an aspect that links target users of ICTs with the inability to understand the language in which these ICTs are written and produced. This is best appreciated when we take into account the fact that these products are sold in the world's major languages, to the total exclusion of indigenous populations of Africa. For instance, the Firefox web browser is available in 40 different languages among which the African indigenous languages do not feature. Most Ipod products and PDAs that originate from the United States have manuals with very few language options. Sometimes, the number is as few as two. The implication of this is that the very diverse indigenous populations of Africa are compelled to use products they do not fully understand: either they underutilise the product or overuse it or use inappropriately. This abnormal usage has many implications which include the most crucial - the inability of the ICTs to deliver on the promise as a factor that aid socio-economic development. 
The threat of a domineering foreign language among indigenous population is real around the world and can be contextualized in two forms. First, it renders an indigenous language vulnerable to extinction as seen in Australia, for example, indigenous languages are, with each passing day, giving way to English. A classic example is Dyirbal. In a study which lasted between 1963 and 1989, the researcher noticed that 'younger people have switched to English....and has seen Dyirbal contract in lexical and grammatical complexity as it has moved toward an inevitable extinction' (Dixon, 1991:183). Secondly, most locals who succumb to the foreign language, either by omission or commission, often end up as lukewarm speakers and writers. This is demonstrated in the use of ICTs where the inability to successfully apply them is simply traceable to the incomprehensibility of the manual.

The minoritisation process, characterised by the refusal of ICT product manufacturers to acknowledge the languages of indigenous populations, is traceable to many factors. Besides the fact that indigenous languages are considered economically unviable, technological determinism also comes into play. This is whereby designers and producers of ICTs make linear assumptions about user prejudices and idiosyncrasies with regard to adoption of technological innovations. This linear approach, which applies one-size-fits-all systems to products, has significantly undermined the often trumpeted benefits of ICTs. By using mainly the major world languages as ICT-oriented languages, where recall of what indigenous people read is difficult, (Mecartty, 2001:265), ICT practitioners are qualified to be accused of elitist and exclusionary practices which hinder access of the affected people to learning, thereby hampering empowerment and consequently promoting a dismal socio-economic development. There is an order of difficulty (Day, Gallimore, Tharp, Chan \& Connor, 1978:181) that is concomitant with the learning of these foreign languages and which ICT producers do not seem to appreciate.

This discriminatory process becomes more manifest if world language statistics are put in perspective. The Italian language is among the 27 languages used by Microsoft Office - a bouquet of several applications produced by Microsoft Incorporated. Italian is spoken by some 60 million people who are found mainly in Italy and in some tiny areas of Switzerland and Croatia. There are many African languages which come close to this Italian figure. Hausa, for instance, is spoken by nearly 70 million people, Swahili is spoken by no less than 100 million, Yoruba by 40 million and quite a few others. Microsoft Office does not give these languages the kind of priority accorded English or French. The implication of this is that the indigenous population who speak these languages are compelled and in some cases coaxed to access software applications in languages which, fundamentally, are alien to them. Their access, therefore, is determined by the depth of their knowledge of a foreign language which in most cases they cannot fully understand. This is a challenge that has to be tackled if ICTs are to be an efficient agent of socio-economic development.

\section{Elitist language preponderance and the predisposing factors}

An examination of the prevalence of elitist languages is germane to help determine the justification behind the neglect of the indigenous languages in most ICTs. The English language is used as an archetype of the elitist scenario in this paper, owing to the fact that it is also the 
lingua franca in many African countries including Nigeria as well as sharing several characteristics with other elitist languages.

English is a language of conquest. When Britain consolidated its grip and amalgamated the Northern and Southern Protectorate of Nigeria in 1914, English automatically became the official language. Government business was conducted in English and it remained the ultimate means of communication in spite of the indirect administration style which features some element of local language input by which local resources were mobilised to be transported to service the on-going industrial revolution in Europe. While English became the victorious language, the indigenous languages became the vanquished ones and they seem to have remained so to this day.

The variegated conquests that accompanied British colonialism had a profound consequence. This is demonstrated among the several ethnic groups, countries and regions embracing English as the official medium of communication. The pluralism has resulted in many forms of English with each of these affirming itself as a de facto system that has divorced itself from the primary English of the Judeo-Christian heritage or the Queen's English. The Englishness of each English form is embedded in a sociolinguistic context and this is clearly decipherable when compared to that of the traditional bases in England. Bhatt (2001:427-528) notes:

The field of study of world Englishes-varieties of English used in diverse sociolinguistic contexts-represents a paradigm shift in research, teaching, and application of sociolinguistic realities to the forms and functions of English. It rejects the dichotomy of US (native speakers) vs THEM (nonnative speakers) and emphasizes instead WE-ness.

Platt, Weber \& Ho (1984:1) also stress the profound spread of English, describing it as 'the most striking example of "language expansion" of this century if not in all recorded history. It has far exceeded that other famous case, the spread of Latin during the Roman Empire.' Although English is not the world's most widely-spoken language (Mandarin Chinese is), it has remained the most profound by virtue of its global spread. All kinds of Englishes now abound: American English, South African English, Nigerian English, Ghanaian English and so forth. Any of these is a kind of English that is in communion with the ancestral home (England) but still carries the weight of the new experience that suits the new surroundings (Achebe, 1966:22). Such English is nativised, yet claims to be original. This nativised English is that spoken by the local elite class.

The consequence of this sociolinguistic pluralism is immense: English did not only become the language of politics and socialisation, it also turned out to be the medium of communication in business and economic matters. However, it should be stressed that the United Kingdom and the United States, where English is more fundamentally grounded, produce the bulk of the goods and services which are exported into those countries that have their own Englishes fluently spoken and written by only the minority which in many cases belong to the elite class as earlier noted. This pluralism has only succeeded in creating a class of select few who relish speaking and 
writing English - far distinct from an army of strugglers who are neither here nor there when it comes to understanding the language, and another army who are illiterates when it comes to English but impeccable in terms of their mother tongues.

Another major factor responsible for the rise of English is that the custodians of indigenous languages are not aggressive about preserving or promoting the use of their languages. The defeatist attitude which prevails as a result of the overbearing resort to English as a means of communication in business and politics is a legacy that is detrimental to African culture and traditions. In many African societies, the means of spread and transfer of knowledge in the mass media are either non-existent or are existent as though they are not. Where they are existent, they are not patronised by the primary target audience.

The Nigerian Reading Association and Association of Nigerian Authors have expressed a deep concern over the dwindling reading culture which discourages prospective investors from establishing local journals and periodicals (Enemaku, 2006:233). Besides the problem of finding readers who are ready to buy or read, another major challenge is that prospective advertisers prefer to advertise in English language journals than in community or indigenous newspapers as demonstrated in the instability and death of many home publications (Nnabuihe \& Ikwubuzo, 2006:43). The low prospects of advertisements in indigenous media are echoed by Oso (2006:192) who asserts that Iwe Irohin, which is regarded as a Yoruba cultural media base and one of the largest circulating indigenous publications in Nigeria sells only 3,000 copies and that none of the newspaper editions published in 2004, for instance, carried any advertisement. The trend is for advertisers to patronise English language newspapers and many of which claim to be national dailies. This cultural dislocation has further entrenched English as the language to beat thus beating the indigenous systems into subservience.

It is necessary to point out the fact that indigenous language degeneration cannot be totally blamed on the overbearing influence of the English language and its promoters. It has also to do with the neglect that indigenous people themselves have accorded their culture. The elitist tendencies that are associated with Africans who can write and speak English fluently have discouraged the local people from preserving their own languages. It has been found that the more educated or elitist an African is, the less they speak, write or buy into their indigenous languages (Salawu, 2004:213). This elitism is defined in terms of Western education either from Europe or America. Leading Kenyan novelist Ngugi Wa Thiong'o rubs it in this way: 'Whereas you see today people identify themselves with that which is removed from them. That which is near them, they don't want to identify with’ (Eyoh, 1986: 112).

The risk of cultural emasculation of indigenous languages has indeed long been a source of concern and there are a few cases to show that people are actually taking steps to stem the sociolinguistic regression. Even when a concerned person was seen taking action in stopping the slide, one subjective reason had been found to underpin such an action. For instance, Henry Townsend, a Christian evangelist, has being credited in history as the founder of the first indigenous language in Nigeria and indeed Africa - Iwe Irohin Yoruba fun Ara Egba ati Yoruba - 
established in 1859. Townsend, who came to Nigeria in the company of a fellow evangelist, Andrew William, entered Nigeria through Badagry Town in December 17, 1842 and was sent by Sierra-Leone-based Church Missionary Society, to spread Christianity in Africa. He was to take advantage of the translation of the Yoruba Bible from English, (by a freed slave - Samuel Adjai, Crowder) under the auspices of British and Foreign Bible Society (Odutola, 2006:43).

According to Townsend (Uche, 1989:92): 'I have set on foot a Yoruba newspaper... My objective is to get people to read... to beget the habit of reading.' This statement suggests that Townsend was out to promote an indigenous culture (or language) - Yoruba. But going by the objective of Anglican Church who sent him, the ultimate objective was to spread the Christian religion in the local language as doing that in English at that time was difficult or practically impossible due to the relative newness of the language. Townsend's objective on the surface was to promote culture but the real underlying goal was to promote religion which could also have been done had an alternative language been possible.

Indigenous language deterioration is therefore a convergence of a domineering foreign force and a lackadaisical local attitude of which one of the consequences is that ICTs that abound in Africa rarely take into cognizance the local dimensions of people's culture.

\section{Indigenous languages, ICTs and globalisation}

While it is possible that the socio-linguistic degeneration is not wholly blamed on foreign domination, it is necessary to stress that the force of English and its propaganda tools, as reflected in ICTs, operate in the context of globalisation which aims at bridging the Global Divide. It should be stressed that the challenge of Digital Divide is not simply about accessibility, differential in the use of computer among unequal sets of people, it is better appreciated as a social division between those who are very involved in technology and those who are not very involved. ICTs are a potent enabler of globalisation owing to the fact that they are gradually creating a global attitude. If globalisation had been seen as a commonly-held concern where the interest of the majority of the world's population is involved and these people are advocating that interest or can be seen to be doing so, it would have been a globally acceptable perspective. However, globalisation is believed in many quarters, especially in the developing countries, to be an agenda to foist Western values on the rest of the world. In this case, globalisation is presented as the wise or superior interest because of its inherent wisdom and desirability (Sorauf, 1957:621) by those who are championing it.

This has a severe implication for the indigenous cultures and their peculiarities because they are depicted as inferior and are not in any way imperative. These peculiarities are automatically perceived as an antithesis and a road block to an emerging unidirectional world. Indigenous cultures therefore pale into insignificance and with the backing of the information technologies as manifested in Internet and the World Wide Web, they degenerate into irrelevance and then inconsequentiality. Salawu (2006:3) paints the picture in this manner: 
It is no gainsaying that the new information technologies... have brought about better communication across the globe and better flow of information about happenings around the world (though it is still argued that the flow is imbalanced), the fact that they are a veritable channel of 'cloning' cannot be ignored. Most people of the 'fringe' [indigenous] cultures, without them knowing it, have, unwittingly, become cloned Americans or Westerners, all in the name of globalization or modernization. For whatever may be said, all we know is that a 'cloned' being is never a natural or a real being.

Language is one of the most potent variables in acculturation. ICTs are conveyed to Africans mostly in Western languages and have, therefore, become a vehicle of cultural emasculation as they offer the platform for indigenous commitment to Western ways of meaning and value formation systems. From the foregoing, it is clear that globalisation via ICTs in their current forms, which promotes the preponderance of foreign language and culture but wishes away indigenous systems, can hardly be a solution to the socio-economic and cultural challenges that are confronting Africa. The designers and constructors of ICT infrastructure, as a result of technological determinism, overrate Western culture in their manuals as demonstrated in the preponderance of American or European languages and undermine indigenous African culture. It means, therefore, that cross cultural communication through ICTs is open to divergences of beliefs, attitudes, perceptions, power relations, meaning systems and behavior norms. This susceptibility starts as contradictions and could or then wind up as conflicts (Giddens, 1984:1989).

\section{Degenerating indigenous language culture and Western corrective initiatives}

The reality of extinction, which characterises the legion of indigenous languages, has exacerbated some remedial actions on the part of ICT makers and advocates. For instance, there is the attempt by Microsoft to incorporate some major African languages into its software platforms, especially its operating systems - Windows - and applications - Microsoft Office. It is necessary to stress at this point that only major indigenous languages are involved. The term 'major' here could mean those languages that are spoken by no fewer than 40 million people in the continent. Such languages will include Swahili, Hausa, Yoruba, Arabic, and a very few others. Evidence also exists as proof that search engines, especially Google, are establishing platforms for local languages in Africa. Google indigenous language versions include Yoruba, Hausa, Zulu, Swahili, among others and are creating some impression of rejuvenation and revival especially among the speakers of those languages.

Three pertinent questions emerge at this point. First, what is the proportion of these 'lucky' languages in the entire indigenous linguistic system? Second, how effective is this policy? Third, what is the implication of these Western corrective measures on the unity of indigenous language speakers? The answer to the first question is not far-fetched. UNESCO reckons that some 90 percent of the world's 6,000 languages (Nowak, 2000:1615) are not represented on the internet and many of these unrepresented languages are getting extinct (Lacey, 2004:2). The few 
languages that have been considered in these corrective measures only form a tip of the iceberg and the question of what becomes of the remaining ones will have to be answered.

Besides that, the choice of some major indigenous languages for this experimental project has good potential to further imperil the often fragile unity among indigenous people. For instance, in Nigeria, the three major languages - Hausa, Yoruba and Igbo - spoken by not less than 100 million are being viewed by other millions of minority people as tools of domination. This population is sharply contrasted with the 50 million agglomerated number of no fewer than other 200 ethnic groups in the country. The speakers of these three languages and their leaders have carved out a triangulation which signposts developments in political, socio-economic and cultural lives of Nigerians as well as to determine the destinies of the minorities. One implication of this is that the providence of Nigeria as a polyglot is determined mainly on the terms of this overbearing tripod. Another is that whenever each of these big three sneezes, the polity is sure to catch cold and its case is treated with dispatch, whereas if any minority is involved, its case may drag on for a long time. Two clear cases illustrate this.

On June 12 of 1993, Moshood Abiola, from the Yoruba ethnic stock contested the presidential election and won a landslide victory on the platform of the Social Democratic Party (SDP). Then the military junta, headed by Ibrahim Babangida, annulled the election with no justifiable reason. There was a massive protest with much of it coming from the Yoruba region of the country. The nation was plunged into chaos that was about to lead to national disintegration. In the ensuing confusion, two regimes which were installed did not succeed and the head of one of them, General Sanni Abacha, was assassinated under mysterious circumstances. Abiola was also killed in the mist of the anarchy. At that point, it was clear that a war could erupt. A military regime, headed by Abubakar Abdusalam, came to power and resolved that Yoruba should be the next head of state. The next political dispensation saw Olusegun Obasanjo, another prominent Yoruba man and a former military head of state elected in 1999 as the president and commander-in-chief of Nigeria's armed forces. And then calm returned to the nation.

The case of Niger Delta illustrates the futile struggles of the minorities in Nigeria. Niger Delta produces the oil from where roughly 90 percent of Nigeria's foreign exchange is earned. Ever since oil was discovered in commercial quantities in 1958, the area had not really enjoyed any dividends as environmental degradation, pollution and poverty have always been the story to tell. According to The Economist (1996:48), 'people complain fiercely... that their wealth and their future have been stolen.' The inhuman treatment which is perpetrated by both the government and oil companies, has continued to this day. The violent protests and the militancy that now characterise the agitation of the minorities whose land oil is being pumped, have not really made any significant change in the psyche of big tribes toward the minorities. This would not have been the case had one of the big three ethnic groups been affected.

Therefore, the attempt by ICT organisations such as Google and Microsoft to use big ethnic groups such as Yoruba, Hausa and Swahili as archetypes runs the risk of aggravating disunity and deglobalisation and further frustrating smaller indigenous groups. This is because the 
minority may tend to think that it is an attempt to perpetrate the weight of these tribes on them and further marginalise them into oblivion.

\section{Google's intervention and results}

The next issue is if these interface initiatives are effective. Elaborate studies will have to be conducted in order to generally determine if the Western interventionist measures are working and this will not come cheaply as all research hands must be on deck in order to achieve anything close to success. However, the outcome of a study conducted on the Yoruba edition of Google by this author suggested that more still has to be done or that solution to the problem lies elsewhere.

Google Naijiria - or more appropriately Google Yoruba - (www.google.com/intl/yo/), was discovered in 2006. It is an interface to the original website Google.com. Google Yoruba, the first local Nigerian language website to be undertaken by Google, is a product of history. Yoruba people, who are found in nine of Nigeria's 36 states, occupy the south-west of the country. Yoruba people are home to the first newspaper in Africa, the first television station in Africa, the first radio station in Nigeria and now the first Google website interface in Nigeria. Yoruba are reputed to be the most educated and urbanised in Nigeria and the bulk of media and commercial advertisements and originate from their area.

While print and broadcast media are successful, the same cannot be said of the Internet with regard to Google's intervention. In the study carried out twice in 2006 and 2007 through a panel design to determine the relevance of Google Yoruba to its target population, results were not encouraging. The study criteria were based on the audience expectations from a web site which are categorised into fundamental, training, conventional, personal, and contextual (William, 2004:57). The contextual expectation refers to the packaging of information in particular contexts in order to enhance the comprehension of information that is being passed across. Personal expectations have to do with those particular benefits that are available to different parts or constituents of your audience. Expectation by convention refers to those communicative customs and practices on the cyberspace that can be assessed by an audience just like their counterparts elsewhere. The fundamental expectation is operationalised in terms of Google's ability to communicate to its audience in the language it understands. The training dimension is indicated when the website is presented to the visitor in a way that increases his or her interest, skill and knowledge of internet especially by the use of available tools. Here the audience can tell whether or not it is comfortable to surf the website.

The results showed that Google Yoruba scored low in all the five categories. The rating of relevance among five demographics was highly insignificant in the two surveys: $\left(F_{(4,710)}=.530\right.$, $p<.714)$ in 2006 and $\left(F_{(4,709)}=.181, p<.948\right)$ in 2007. The factors identified as responsible for this dismal performance in this study include absence of crucial information access points such as those found in google.com, the inability of Google to capture Yoruba orthographical nuances, which complicates the mechanism of meaning transfer (Nicovich and Cornwell, 2001: 147), and the difficulty by the website audience in localising the Google vernacular presentation in any of the Yoruba dialects. The site lacks the savvy, upbeat and friendly style characteristic of the normal Lagos Yoruba which is probably the most commonly used in the south-west and the 
conservative Ibadan variety which is pervasive in only two of the five states studied and is less universally acceptable. Undermining the importance of audience analysis has been a potent factor in website failures as many organisations neglect due process of market research in an unprofitable rush to establish their presence online (Nadillo, 1998).

\section{Conclusion: preservation and survival strategies of indigenous languages}

What is the way out of this indigenised quagmire? Two routes to a probable solution are discernible: afrocentricism and afrocomplementarism. In the afrocentric school, phenomena are viewed from the perspective of the African (Asante, 1991; Verharen, 1995; Winters, 1994). According to Mazama (2001:388), 'it is also a systematic displacement of foreign paradigms and their conscious replacement with the ways that are useful and of interest to Africa.' Afrocentric drivers stress that any research that pertains to Africa should be carried out within the African context whether or not it is in line with the norms of the Western tradition of enquiries.

When applied to the issue at stake here, it means that Africans should be ready to forge a way out for their languages using the resources available within their domain. It would mean creating a superstructure on which they will build to checkmate the constant and unproductive intrusion of foreign culture. This superstructure will come in the form of their own technology and contents.

Applying the concepts of afrocentrist policy in these contemporary times can be erroneous. This is because Africans, as yet, are not empowered enough to create such a superstructure that can match the century-old Western technologies - Africans, in fact, would require a miracle to catch up. The technological base of most African countries is dependent on the West and the economy of many developing countries is easily doomed without the support of Americans or Europeans. Therefore, going the ICT way alone may not be feasible for now.

Afrocomplementarism (Omojola, 2008:176), which is the alternative route that this article is promoting, recognises the importance of a globalising world and shies away from the elimination by substitution perspective endorsed by afrocentrism. The complementary approach appreciates the technological feat of the West but encourages a massive indigenous content development by Africans especially for the internet. The fact of the matter is that there is a limit to what promoters of Western ICTs can do to promote Africanised contents for Africans. This has to be developed by Africans who must establish themselves firmly on the internet with convincingly documented contents. The drivers of ICTs can be compelled to formulate programmes that will harness these indigenous contents. If these local treasures are archived and put on the internet, interfaces can be created to enable other interested users access to them. At the local end, the indigenous peoples will have to embark on centripetal development of their languages not only in their local schools, but also through local media such as newspapers, novels and community broadcast systems. Government and concerned institutions can embark on a deliberate language development, planning and evaluation (Woolard \& Gahng, 1990:312; Nahir, 1998:335; Bilaniuk, 2003:48) which involves periodic assessment of values and attitudes towards a language and determination of solution to any deficiency thereof. Moreover, conscious steps taken by 
indigenous people to understand their languages will go a long length in making them relevant in the global scheme of things. After all, charity begins at home.

\begin{abstract}
About the author
Dr. Oladokun Omojola is an assistant professor in the Department of Mass Communication at Covenant University, Ota, Nigeria.
\end{abstract}

\title{
Contact information
}

dokunomojola@yahoo.com.

\section{References}

Achebe C. (1966). Things Fall Apart. London: Heinemann.

Asante, M. (1991). The Afrocentric Idea in Education. Journal of Negro Education, (60), 170179.

Bhatt, R.M. (2001) World Englishes. Annual Review of Anthropology. 30:527-550.

Bilaniuk, L. (2003). Gender, Language Attitudes, and Language Status in Ukraine. Language in Society, 32(1), 47-78.

Cogburn, D. L. and Adeya, C. 1999: 'Globalization and the Information Economy: Challenges and Opportunities for Africa'. Paper presented at the African Development Forum on Globalization and the Challenges of Information Age to Africa, UNECA, Addis Ababa, October 1999.

Day, R. Gallimore, R., Tharp, R., Chan, K. and Connor, M. (1978). Order of difficulty of standard english grammatical features among cultural minority groups in the United States. Anthropology \& Education Quarterly. 9(3), 181-195.

Dixon, R. M. W. (1991). A Changing Language Situation: The decline of Dyirbal, 1963-1989. Language in Society. 20(2):183-200.

Enemaku, O. (2006). The print media among Igala People: Toward a renaissance. In Salawu, A. (Ed.) Indigenous language media in Africa. Lagos: Centre for Black Arts and Civilization. Eyoh, H.N. (1986). Theatre of relevance: An interview with Ngugi Wa Thiong’o. African Theatre Review. 1(2):110-114.

Giddens, A. (1984). The constitution of society. Cambridge (UK): Polity Press. Hoffman D.M. (1989). Language and culture acquisition among Iranians in the United States. Anthropology \& Education Quarterly. 20 (2):118-132.

Kathryn, A., Woolard, K.A. \& Tae-Joong Gahng, T. (1990). Changing language policies and attitudes in autonomous catalonia. Language in Society. 19(3):311-330.

Lacey, M. Using a new language in Africa to save dying ones. Accessed date: www.nytimes.com/2004/11/12.

MacGregor, M. \& Price, E. (1999). An exploration of aspects of language proficiency and algebra learning. Journal for Research in Mathematics Education. 30(4):449-467.

Mecartty, F. H. (2001). The effects of modality, information type and language experience on recall by foreign language learners of Spanish. Hispania. 84(2):265-278.

Mercer, M. (2004). Engineering civil society: ICT in Tanzania. Review of African Political Economy, 31(99):49-64. 
Nadilo, R. (1998). On-line research taps consumers who spend. Marketing Research. 32 (12):12. Nahir , M. (1998). Micro language planning and the revival of Hebrew: A schematic framework. Language in Society. 27(3):335-357.

Nicovich, S. \& Cornwell B. T. (2001). An Internet culture? In Implications for marketing in Internet marketing: Readings and online resources (Richardson, P. Ed). New York: McGraw Hill.

Nnabuihe, C. \& Ikwubuzo, I. (2006). A peep into news publications and reading culture in Igbo language of Nigeria. In Salawu, A. (Ed). Indigenous language media in Africa. Lagos: Centre for Black Arts and Civilization.

Nowak, A.M. (2000). Evolutionary biology of language. Philosophical Transactions: Biological Sciences. 355 (1403):1615-1622.

Odutola, F.B. (2006). Sowing the seed: 40 years of Bible society relevance in Nigeria. Lagos:

Anchor.

Olalekan, A. (2007). Behold, Nigeria’s second storey building. Punch. Accessed 2009-01-28:

http://www.punchng.com/Articl.aspx?theartic=Art20080707082732.

Oso, L. (2006). A political economy of indigenous language press in Nigeria. In Salawu, A. (Ed), Indigenous Language Media in Africa. Lagos: Centre for Black Arts and Civilization.

Platt, J., Weber, H. \& Ho, M.L. (1984). The new Englishes. London: Routledge.

Salawu, A.S. (2004). Social status as a factor for the readership of Yoruba newspapers in

Nigeria. Nordic Journal of African Studies. 13(2):200-215.

Salawu, A. (2006). Paradox of a millieu: Communicating in African indigenous languages in the age of globalization. In Salawu, A. (Ed). Indigenous language media in Africa. Lagos: Centre for Black Arts and Civilization.

Sorauf, F.J. (1957). The public interest reconsidered. The Journal of Politics. 19(4):616-639.

The Economist. 1996-06-48.P. 48.

Uche, L.U. (1989). Mass media, people and politics in Nigeria. New Delhi: Concept.

Verharen, C.C. (1995). Afrocentrism and acentrism: A marriage of science and philosophy, Journal of Black Studies. 26(1):62-76.

Williams, N. (2004). How to get a 2:1 in media, communication and cultural studies. London: Sage Publications.

Winters, C.A. (1994). Afrocentrism: A valid frame of reference. Journal of Black Studies. 25(2): 170-190. 